\title{
Preparation and Properties \\ of Zr-Bearing Sorption Materials Based on Coal Fly Ash Microspheres
}

Tatiana A. Vereshchagina, Ekaterina A. Kutikhina, Yana Yu. Chernykh, Elena V. Fomenko, Elena V. Mazurova, Sergei N. Vereshchagin and Galina N. Bondarenko* Institute of Chemistry and Chemical Technology SB RAS FRC "Krasnoyarsk Science Center SB RAS" 50/24 Akademgorodok, Krasnoyarsk, 660036, Russia

Received 27.02.2019, received in revised form 28.02.2019, accepted 14.07.2019

The influence of hydrothermal conditions on synthesis of analcime and a composite material $\mathrm{ZrO}_{2}$ analcime as well as zirconomolybdate coverings with ion exchange properties was studied using narrow fractions of aluminosilicate microspheres with a high content of a glass phase (91-95 wt. \%). The possibility to synthesize $\mathrm{ZrO}_{2}$-analcime composites of narrow particle size distributions with maximum of about $40 \mu \mathrm{m}$ and $6 \mu \mathrm{m}$ under hydrothermal treatment at $150^{\circ} \mathrm{C}$ was demonstrated starting from microspheres with $\mathrm{Si} / \mathrm{Al}=2.7$ and applying different regimes of a reaction mixture agitation. $A$ microsphere material of a "core-shell" type such as $\mathrm{ZrMo}_{2} \mathrm{O}_{7}(\mathrm{OH})_{2}\left(\mathrm{H}_{2} \mathrm{O}\right)_{2}$ @ $\left(\mathrm{SiO}_{2}-\mathrm{Al}_{2} \mathrm{O}_{3}\right)_{\text {glass }}$ with the nanostructured covering was prepared. Sorption properties of the materials regarding $\mathrm{Nd}^{3+}, \mathrm{Sr}^{2+}$ and $\mathrm{Cs}^{+}$were studied under equilibrium conditions by means of determination of sorption isotherms and their fitting by the Langmuir model. Sorption parameters were determined including distribution coefficients which reach the values of $10^{4}-10^{5} \mathrm{~mL} / \mathrm{g}$.

Keywords: microspheres, analcime, $\mathrm{ZrO}_{2}$, core-shell, zirconomolybdates, sorbents.

Citation: Vereshchagina T.A., Kutikhina E.A., Chernykh Ya.Yu., Fomenko E.V., Mazurova E.V., Vereshchagin S.N., Bondarenko G.N. Preparation and properties of Zr-bearing sorption materials based on coal fly ash microspheres, J. Sib. Fed. Univ. Chem., 2019, 12(3), 347-363. DOI: 10.17516/1998-2836-0132.

(C) Siberian Federal University. All rights reserved

* Corresponding author E-mail address: tatiana@icct.ru; ekaterina_kutikhina@mail.ru 


\title{
Получение и свойства Zr-содержащих \\ сорбционно-активных материалов
}

на основе микросфер летучих энергетических зол

\author{
Т.А. Верещагина, Е.А. Кутихина, \\ Я.Ю. Черных, Е.В. Фоменко, \\ Е.В. Мазурова, С.Н. Верещагин, Г.Н. Бондаренко \\ Институт химии и химической технологии СО РАН \\ ФИЦ «Красноярский научный иентр СО РАН» \\ Россия, 660036, Красноярск, Академгородок, 50/24
}

Изучено влияние условий гидротермального синтеза на получение анальцима и композитного материала $\mathrm{ZrO}_{2}$-анальцим, а также ииркономолибдатных покрытий с ионообменными свойствами с использованием узких фракиий алюмосиликатных микросфер с высоким содержанием стеклофазы (91-95 мас. \%). Продемонстрирована возможность синтеза композиций $\mathrm{ZrO}_{2}$-анальцим с узкими распределениями частии по размеру с максимумами $\sim 40 \mu м$ и 6 $\mu$ путем гидротермальной обработки микросфер с Si/Al=2.7 в присутствии соединения ичикония и щелочного активирующего агента при $150{ }^{\circ} \mathrm{C}$ и различном режиме перемешивания реакционной смеси. Получены микросферические материалы типа «ядрооболочка» состава $\mathrm{ZrMo}_{2} \mathrm{O}_{7}(\mathrm{OH})_{2}\left(\mathrm{H}_{2} \mathrm{O}\right)_{2} @\left(\mathrm{SiO}_{2}-\mathrm{Al}_{2} \mathrm{O}_{3}\right)_{\text {стекло }} \quad$ c наноструктурированным покрытием. Изучены сорбиионные свойства полученных материалов в отношении катионов $\mathrm{Nd}^{3+}, \mathrm{Sr}^{2+}$ и $\mathrm{Cs}^{+}$в равновесных условиях путем построения изотерм сорбции и их аппроксимации моделью Ленгмюра. Определены параметры сорбиии, включая коэффициент распределения, величина которого достигает $10^{4}-10^{5}$ мл/2.

Ключевые слова: микросферы, анальцим, $\mathrm{ZrO}_{2}$, ядро-оболочка, изикономолибдаты, сорбентыл.

\section{Введение}

В условиях развития промышленности и топливно-энергического комплекса поиск и создание эффективных сорбентов для извлечения радионуклидов, тяжелых металлов и органических загрязнений из водных сред остаются одной из актуальных задач современной химии. Немаловажными факторами при выборе сорбента являются его стоимость, простота получения и доступность используемых для синтеза материалов.

В качестве сорбентов катионов металлов широко используются цеолиты, поскольку обладают рядом структурных особенностей, связанных с наличием полостей и каналов определенных размеров, а также катионов, способных к ионному обмену [1-4]. В процессах переработки жидких радиоактивных отходов цеолиты чаще всего выполняют функцию сорбентов радионуклидов цезия и стронция, при этом используются преимущественно такие типы цеолитов, как $\mathrm{NaA}$ (LTA), $\mathrm{NaX}$ (FAU), $\mathrm{NaP}$ (GIS), клиноптилолит (HEU) и шабазит (CHA) [5-8]. 
Анальцим (ANA), как наиболее узкопористый цеолит $\left(\mathrm{D}_{\text {пор }}=2,6 \AA \AA\right)$ по сравнению с другими цеолитами, неспособен при нормальных условиях к сорбции крупных катионов цезия $(\mathrm{r}=1.7 \AA$ 立 [9], но достаточно эффективно осуществляет обмен многозарядных ионов, например, $\mathrm{U}$ и $\mathrm{Th}[10,11]$. Анальцим достаточно легко синтезируется в гидротермальных условиях исходя из чистых химических реактивов [12], природных и техногенных алюмосиликатных материалов - цеолитов [13], глин [14] и алюмосиликатных стекол [15-17], включая полые алюмосиликатные микросферы из летучих зол (ценосферы) [18]. Большинство из представленных видов сырья не обеспечивает получение цеолитного продукта высокой чистоты, который наряду с анальцимом содержит примеси других цеолитов.

В случае использования ценосфер авторами $[18,19]$ продемонстрирована возможность синтеза моноцеолитных фаз с топологией каркаса типа анальцим различного состава, в том числе Cs-содержащих фаз твердых растворов $\left(\mathrm{Na}_{\mathrm{n}} \mathrm{Cs}_{1-\mathrm{n}}\right) \mathrm{AlSi}_{2} \mathrm{O}_{6} \cdot \mathrm{nH}_{2} \mathrm{O}$ (поллуцит, Cs-анальцим) [19] и композитного материала $\mathrm{ZrO}_{2}$-анальцим, в котором частицы аморфного диоксида циркония распределены в объеме цеолитных кристаллов [18]. $\mathrm{ZrO}_{2}$-содержащий цеолитный материал может функционировать, с одной стороны, как сорбент с различными типами сорбционных центров, а с другой - как прекурсор огнеупорной цирконоалюмосиликатной керамики [20], которая имеет потенциал использования в качестве химически устойчивой формы фиксации радиоактивных отходов [21], получаемой в результате фазовой трансформации обменных форм цеолитного материала [22]. В связи с этим возможность варьирования свойств композитного материала $\mathrm{ZrO}_{2}$-анальцим представляет, несомненно, большой практический интерес.

Другим активно развивающимся направлением в области создания сорбентов является получение материалов со структурой «ядро-оболочка», в которых сорбционно-активный компонент наносят на поверхность инертного носителя, например силикатного стекла [23, 24]. Благодаря сферической форме глобул в качестве «ядра» таких структур успешно применяют и ценосферы, а создание функциональных слоев проводят путем кристаллизации на их поверхности цеолитов различных структурных типов ( $\mathrm{NaP}, \mathrm{NaA}$ и/или $\mathrm{NaX}$ ) [22, 25] или синтеза мезопористых оксидов металлов $\left(\mathrm{ZrO}_{2}-\mathrm{MoO}_{3}\right)$ в гидротермальных условиях [26].

Эффективность применения подобных композиций для сорбционного извлечения катионов металлов определяется составом и параметрами пористой структуры покрытия, а также структурными особенностями фазы активного компонента. Так, известный способ нанесения циркономолибдатной пленки на микросферический носитель не обеспечивает однородности покрытия и характеризуется низкой степенью включения молибдена ( $\mathrm{Mo} / \mathrm{Zr} \leq 0.4)$ в циркономолибдат [27]. Наряду с этим известны кристаллические циркономолибдаты стехиометрического состава, $\mathrm{Zr}\left(\mathrm{MoO}_{4}\right)_{2}\left(\mathrm{M}_{2} \mathrm{O}\right) \mathrm{H}_{2} \mathrm{O}\left(\mathrm{M}=\mathrm{Na}^{+}, \mathrm{NH}_{4}^{+}\right)$[27] и $\mathrm{ZrMo}_{2} \mathrm{O}_{7}(\mathrm{OH})_{2}\left(\mathrm{H}_{2} \mathrm{O}\right)_{2}$ [28], содержащие протолитические гидроксильные и аквагруппы, за счет которых эти соединения могут обладать ионообменными свойствами. Однако отсутствие каналов в кристаллической решетке $\mathrm{ZrMo}_{2} \mathrm{O}_{7}(\mathrm{OH})_{2}\left(\mathrm{H}_{2} \mathrm{O}\right)_{2}[28]$ препятствует диффузии катионов в объеме кристалла. Можно ожидать, что уменьшение размера частиц этой фазы, способствующее повышению удельной поверхности материала и, как следствие, площади контакта с сорбатом, будет облегчать ионный обмен. К тому же нанесение пленок сорбционно-активного соединения на поверхность микросферического носителя рассматривается как один из способов получения гранулированной формы порошкового сорбента.

$$
-349-
$$


Целью данной работы является исследование влияния условий гидротермального синтеза на свойства композиции $\mathrm{ZrO}_{2}$-анальцим, а также получение циркономолибдатных покрытий с ионообменными свойствами с использованием узких фракций стеклокристаллических микросфер системы $\mathrm{SiO}_{2}-\mathrm{Al}_{2} \mathrm{O}_{3}$ в качестве подложек и оценка их ионообменных свойств в отношении катионов $\mathrm{Nd}^{3+}, \mathrm{Sr}^{2+}$ и $\mathrm{Cs}^{+}$.

\section{Экспериментальная часть}

Реактивы и материалы. Все химические реактивы, которые применяли в данной работе, были марки ч.д.а.

В работе использовали узкие фракции алюмосиликатных микросфер с содержанием стеклофазы 91-95 мас. \% $\left(\left(\mathrm{SiO}_{2}-\mathrm{Al}_{2} \mathrm{O}_{3}\right)_{\text {стекло }}\right)$, состав которых приведен в табл. 1. На рис. 1 представлены микрофотографии глобул микросфер исходных фракций.

\section{Синтез анальцима и композитного материала $\mathrm{ZrO}_{2}$-анальцим}

Синтез анальцима проводили в процессе гидротермальной обработки при $150{ }^{\circ} \mathrm{C}$ системы $\mathrm{Na}_{2} \mathrm{O}-\mathrm{H}_{2} \mathrm{O}-\left(\mathrm{SiO}_{2}-\mathrm{Al}_{2} \mathrm{O}_{3}\right)_{\text {стелло }}$ мольного состава $1.0 \quad \mathrm{SiO}_{2} / 0.18 \quad \mathrm{Al}_{2} \mathrm{O}_{3} / 0.89 \quad \mathrm{Na}_{2} \mathrm{O} / 65 \quad \mathrm{H}_{2} \mathrm{O}$ при отношении жидкое(ж)/твердое(т)=5:1 (по объему), полученной путем добавления 10 г микросфер НMT1А-0.18+0.08 мм (Образец №1, табл. 1) к 133 мл 1.5М NaOH. Для проведения синтеза ис-

Таблица 1. Макрокомпонентный и фазовый составы (мас. \%) исходных микросфер

Table 1. Macrocomponent and phase composition (wt. \%) of initial microspheres

\begin{tabular}{|c|c|c|c|c|c|c|c|c|c|c|c|}
\hline \multirow{2}{*}{ № } & \multirow{2}{*}{ Образец } & \multirow[b]{2}{*}{$\begin{array}{l}\sum_{j}^{2} \\
\vdots \\
\vdots \\
0\end{array}$} & \multirow[b]{2}{*}{ 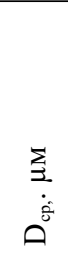 } & \multicolumn{3}{|c|}{$\begin{array}{c}\text { Макро- } \\
\text { компонентный } \\
\text { состав }\end{array}$} & \multirow{2}{*}{ 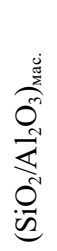 } & \multicolumn{4}{|c|}{ Фазовый состав } \\
\hline & & & & $\stackrel{0}{\infty}$ & $\stackrel{\infty}{\gtrless}$ & 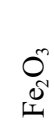 & & 背 & 売 & $\begin{array}{l}\text { 㝵 } \\
\text { 量 } \\
\text { 氙 }\end{array}$ & 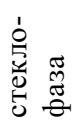 \\
\hline 1 & HMT1A-0.18+0.08 мм & 0.38 & 146 & 67.6 & 21.0 & 3.0 & 3.2 & 3.4 & 0.8 & 0.5 & 95.4 \\
\hline 2 & $\begin{array}{l}\text { HMH1A }-0.18+0.08 \text { мм } \\
-0.16+0.125 \text { в/в вак }\end{array}$ & 0.38 & 144 & 67.5 & 21.3 & 3.5 & 3.2 & 6.7 & 1.5 & 0.3 & 91.5 \\
\hline
\end{tabular}
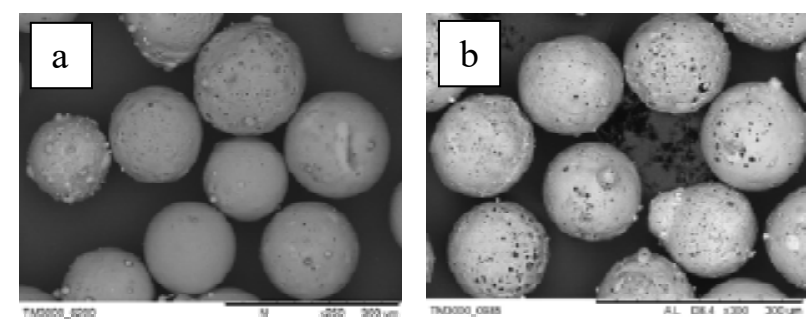

Рис. 1. РЭМ-снимки исходных микросфер: a - НМТ1А $-0.18+0.08$ мм; b - НМН1А $-0.18+0.08$ мм $-0.16+0.125$ в/в вак

Fig. 1. SEM images of initial microspheres: a - HMT1A $-0.18+0.08 \mathrm{~mm}$; b - HMH1A $-0.18+0.08 \mathrm{~mm}$ $-0.16+0.125 \mathrm{v} / \mathrm{v}$ vac 
пользовали два типа автоклава с тефлоновым вкладышем. В одном из них (автоклав А1) перемешивание реакционной смеси осуществлялось путем вращения реактора в вертикальной плоскости с частотой 30 об/мин при длительности синтеза 68 ч, в другом автоклаве (автоклав A2, BELUGA, Premex AG, Швейцария) суспензия перемешивалась с помощью мешалки в горизонтальной плоскости со скоростью 50 об/мин в течение 48 ч. По окончании синтеза осадки отфильтровывали, отмывали дистиллированной водой до отрицательной реакции на ионы $\mathrm{Cl}^{-} \mathrm{c}$ выделением осадков центрифугированием и сушили при $110{ }^{\circ} \mathrm{C}$ в течение 4 ч. Отсутствие/наличие ионов $\mathrm{Cl}^{-}$контролировали с помощью $0,1 \mathrm{M} \mathrm{AgNO}_{3}$. Далее полученные продукты рассеивали на ситах (Виброгрохот ПЭ-6800, Россия) с размером ячеек 36, 71, 100 и $224 \mu$ м. Основная доля продуктов синтеза в автоклавах $\mathbf{A 1}$ и $\mathbf{A 2}$ сосредоточилась во фракции 100-224 $\mu$ м - 49 и 95 мас. \% соответственно.

Синтез композитного цеолита проводили в аналогичных условиях $\left(150{ }^{\circ} \mathrm{C}, 48\right.$ ч) в двух автоклавах $\mathbf{A 1}$ и $\mathbf{A 2}$ из реакционной смеси состава $1.0 \quad \mathrm{SiO}_{2} / 0.18 \mathrm{Al}_{2} \mathrm{O}_{3} / 0.89 \mathrm{Na}_{2} \mathrm{O} / 0.15 \mathrm{ZrO}_{2} / 65$ $\mathrm{H}_{2} \mathrm{O}$, которую получали путем добавления 5 г аммонийно-цитратного комплекса циркония (IV) к суспензии микросфер в $1.5 \mathrm{M} \mathrm{NaOH}$ (ж/т=5:1). В автоклаве $\mathbf{A 1}$ перемешивание реакционной смеси осуществлялось путем вращения реактора в вертикальной плоскости с частотой 30 об/мин, а в автоклаве $\mathbf{A 2}$ суспензия перемешивалась с помощью мешалки в горизонтальной плоскости со скоростью 30, 50 и 200 об/мин. По окончании синтеза осадки отфильтровывали, отмывали дистиллированной водой до отрицательной реакции на ионы $\mathrm{Cl}^{-}$с выделением осадков центрифугированием и сушили при $110{ }^{\circ} \mathrm{C}$ в течение 4 ч. В результате центрифугирования твердый продукт синтеза в автоклаве А1 разделился на два слоя - серый (А1-С) и белый (А1-Б), которые были выделены индивидуально. Все продукты рассеяли на ситах с размером ячеек 36 и $71 \mu$ м. Основная доля продуктов синтеза в автоклаве $\mathbf{A 1}$ сосредоточилась во фракциях 36-71 $\mu$ м (71 мас. \% A1-С) и > $71 \mu$ м (97 мас. \% А1-Б), а в автоклаве $\mathbf{A 2}-$ во фракции $<36 \mu$ м (85 мас. \%).

Для удаления свободного диоксида циркония фракцию < 36 нм обрабатывали ультразвуковым источником (Cole-Parmer Instruments CPX-750, США) в течение 30 мин с последующей декантацией и сушкой осадка при $80^{\circ} \mathrm{C}$ в течение 3 ч.

Синтез композищии $\mathrm{ZrMo}_{2} \mathrm{O}_{7}(\mathrm{OH})_{2}\left(\mathrm{H}_{2} \mathrm{O}\right)_{2} @\left(\mathrm{SiO}_{2}-\mathrm{Al}_{2} \mathrm{O}_{3}\right)_{\text {стекло }}$

В качестве прекурсора микросферической подложки использовали узкую фракцию полых микросфер НМН1А $-0.18+0.08$ мм $-0.16+0.125$ в/в вак (Образец №2, табл. 1). Микросферы подвергали травлению в растворе $\mathrm{NH}_{4} \mathrm{~F}-\mathrm{HCl}$ согласно методике [29] с выделением продукта со сквозной открытой пористостью, который обрабатывали кипящей $1 \mathrm{M} \mathrm{HCl}$, отмывали дистиллированной водой и сушили при $100{ }^{\circ} \mathrm{C}$. В результате получены полые глобулы с пористой стенкой с размером пор 1-5 $\mu$ м.

Синтез $\mathrm{ZrMo}_{2} \mathrm{O}_{7}(\mathrm{OH})_{2}\left(\mathrm{H}_{2} \mathrm{O}\right)_{2}$ на поверхности микросферического носителя был осуществлен в две стадии. Сначала в условиях, описанных в работе [30], провели осаждение на подложку мезопористого диоксида циркония $\left(\mathrm{mZrO}_{2}\right)$ с получением композиции $\mathrm{mZrO} 2 /\left(\mathrm{SiO}_{2}-\mathrm{Al}_{2} \mathrm{O}_{3}\right)_{\text {стекло }}$, которую затем подвергли гидротермальной обработке в $1 \mathrm{M} \mathrm{Na}_{2} \mathrm{MoO}_{4}(\mathrm{pH}=1.5)$ при $150{ }^{\circ} \mathrm{C}$ в течение 72 ч с последующим выделением твердого продукта методом фильтрации, отмывки в дистиллированной воде и сушки на воздухе.

$$
\text { - } 351-
$$


Методика экспериментов по сорбиии. Навески образцов сорбентов $(0.05 \pm 0.005$ г) помещали в пластиковые контейнеры и заливали 40 мл водного раствора, содержащего заданные концентрации катионов неодима, стронция или цезия (от 0.5 до 50 мг/л). Растворы периодически взмучивали и выдерживали при комнатной температуре 24 ч.

Равновесные фазы разделяли фильтрованием, фильтрат анализировали на содержание катионов металлов.

Равновесную сорбционную емкость ( $\left.\mathrm{A}_{\mathrm{p}}, \mathrm{Mг} / \Gamma\right)$ рассчитывали по разности концентраций в исходном и равновесном растворах (1):

$$
A \mathrm{p}=\frac{\left(C_{0}-C_{p}\right) \cdot V}{m}
$$

где $\mathrm{C}_{0}$ - исходная концентрация $\mathrm{Me}^{\mathrm{n}+}$ в растворе, $\mathrm{мг} / л ; \mathrm{C}_{\mathrm{P}}-$ равновесная концентрация $\mathrm{Me}^{\mathrm{n}+}$ в растворе, мг/л; V - объем исходного раствора, л; $\mathrm{m}$ - масса навески сорбента, г.

По экспериментальным данным построены изотермы сорбции, которые были аппроксимированы уравнением Ленгмюра (2) [31]:

$$
\mathrm{A} p=\mathrm{a}_{m} \frac{\mathrm{bC} p}{1+\mathrm{bC} p},
$$

где $\mathrm{a}_{\mathrm{m}}$ - емкость сорбента при насыщении, мг/г; b - константа уравнения Ленгмюра, л/мг;

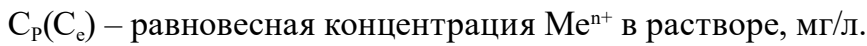

На основании полученных данных рассчитывали такие параметры сорбции, как коэффициент распределения $\left(\mathrm{K}_{\mathrm{D}}\right.$, мл/г) для линейной части изотермы при $\mathrm{C}_{\mathrm{p}}<1$ мг/л и эффективность сорбции (Е, \%) с использованием уравнений (3) и (4) соответственно:

$$
\begin{aligned}
& K_{D}=\frac{C_{0}-C_{p}}{C_{p}} \cdot \frac{V}{m}, \\
& \mathrm{E}=\frac{\mathrm{C}_{0}-C_{p}}{C_{0}} \cdot 100 \% .
\end{aligned}
$$

Методы исследования. Химический состав узких фракций микросфер определяли согласно ГОСТу № 5382-91 [32].

Фазовый состав образцов выявляли методом порошкового рентгенофазового анализа с использованием подхода Ритвельда [33] и метода минимизации производной разности (МПР) [34]. РФА-спектры записывали на дифрактометрах ДРОН-3 и PANalytical X'Pert PRO MPD (Нидерланды) с твердотельным детектором PIXcel и вторичным графитовым монохроматором для $\mathrm{CuK}_{\alpha}$-излучения.

Текстурные характеристики полученных образцов определяли на сорбционном анализаторе удельной поверхности NOVA 3200e (Quantachrome Instruments, США) методом низкотем-

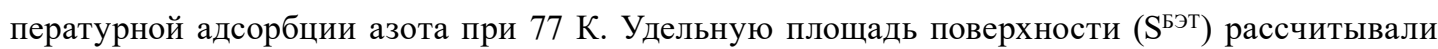
методом Брунауэра - Эммета - Теллера (БЭТ) [31].

Электронно-микроскопические исследования образцов и определение элементного состава их поверхностей осуществляли с помощью настольного растрового электронного микроскопа (РЭМ) ТМ-3000 и S-5500 (Hitachi, Япония), оборудованного системой микроанализа Bruker, 
включающей энергодисперсионный рентгеновский спектрометр (ЭДС, EDX) с детектором XFlash 430H и программным обеспечением QUANTAX 70. Рентгеноспектральный микроанализ (РСМА) проводили при ускоряющем напряжении 15 кВ в режиме отображения. Время накопления данных составляло 10 мин.

Термический анализ выполняли на приборе STA Jupiter 449C/AELOSQMS403C (Netzsch, Германия). Эксперименты проводили в потоке смеси $20 \% \mathrm{O}_{2}-\mathrm{Ar}$ в платиновых тиглях с перфорированными крышками при скорости нагрева $10{ }^{\circ} \mathrm{C} \cdot \mathrm{Mин}^{-1}$. Качественный состав отходящих газов оценивали по изменению интенсивности ионов с m/z $18\left(\mathrm{H}_{2} \mathrm{O}\right)$.

Концентрацию катионов неодима в фильтратах после сорбции определяли методом спектрофотометрии (КФК-3, Россия) с применением органического реагента Арсеназо I, который образует с ионом неодима интенсивно окрашенные хелаты [35]. $\mathrm{pH}$ растворов контролировали стеклянным электродом ЭСК-10601/7 на универсальном иономере Анион-4100 (ООО НПП «Инфраспак-Аналит», Россия). Концентрации катионов $\mathrm{Cs}^{+}$и $\mathrm{Sr}^{2+}$ устанавливали методом атомной абсорбционной спектрометрии (AAC) на приборе AAS-30 (Carl Zeiss, Germany).

Распределение частиц по размеру определяли путем измерения среднего диаметра частицы на цифровых снимках с использованием программы «Msphere» [36]. Цифровые снимки в отраженном и проходящем свете получали на оптическом микроскопе Axioskop 40 (Carl Zeiss, Германия), оснащенном окуляром Zeiss W-PI 10x/23 и цифровой камерой Canon Power Shot А640. Данные по размеру частиц получены на основании анализа 5364 снимков.

\section{Результаты и обсуждение}

Анальцим и композитный материал $\mathrm{ZrO}_{2}$-анальцим. Для получения цеолитов с прогнозируемыми свойствами (морфология, размер частиц, чистота фазового состава) наряду с определенным составом реакционной смеси важна также температура, продолжительность синтеза, скорость перемешивания, отношение жидкое/твердое и пр. [37]. В данной работе в качестве варьируемого параметра изучали влияние режима и скорости перемешивания на свойства полученного продукта.

Как видно на РЭМ-снимках (рис. 2), для системы $\mathrm{Na}_{2} \mathrm{O}-\mathrm{H}_{2} \mathrm{O}-\left(\mathrm{SiO}_{2}-\mathrm{Al}_{2} \mathrm{O}_{3}\right)_{\text {стекло }}$ в продуктах обоих синтезов присутствуют кристаллы с икоситетраэдрическим габитусом, присущим цеолиту с топологией каркаса типа анальцим (ANA) [38].

По данным рентгеноспектрального микроанализа, мольное отношение $\mathrm{Si} / \mathrm{Al}$ в кристаллах равно 1,9 (A1) и 2,0 (A2), что соответствует диапазону изменения $\mathrm{Si} / \mathrm{Al}$ в анальциме. Основными типами частиц в продуктах являются агломераты кристаллов анальцима с остатками стекла микросфер (рис. 2a), обнаруженные во фракциях 100-224 и 71-100 $\mu$ м, или друг с другом с сохранением сферической формы исходных микросфер (рис. $2 c, d$ ). Во фракциях 36-71 и < 36 нм продукта А1 концентрируются фрагменты микросфер с прикрепленными кристаллами анальцима, а также свободные кристаллы, размеры которых варьируют от 3-5 до 30-50 $\mu$ м (рис. $2 b$ ). Отличительной чертой синтеза в автоклаве $\mathbf{A 2}$ является кристаллизация анальцима значительно меньших размеров, чем в автоклаве A1. Фактически продукт синтеза - полые микросферы, стенка которых состоит из кристаллов анальцима размером 2-7 $\mu$ м, при незначительном содержании остаточной стеклофазы. Таким образом, изменение режима перемешивания оказало влияние, прежде всего, на степень превращения стекла 

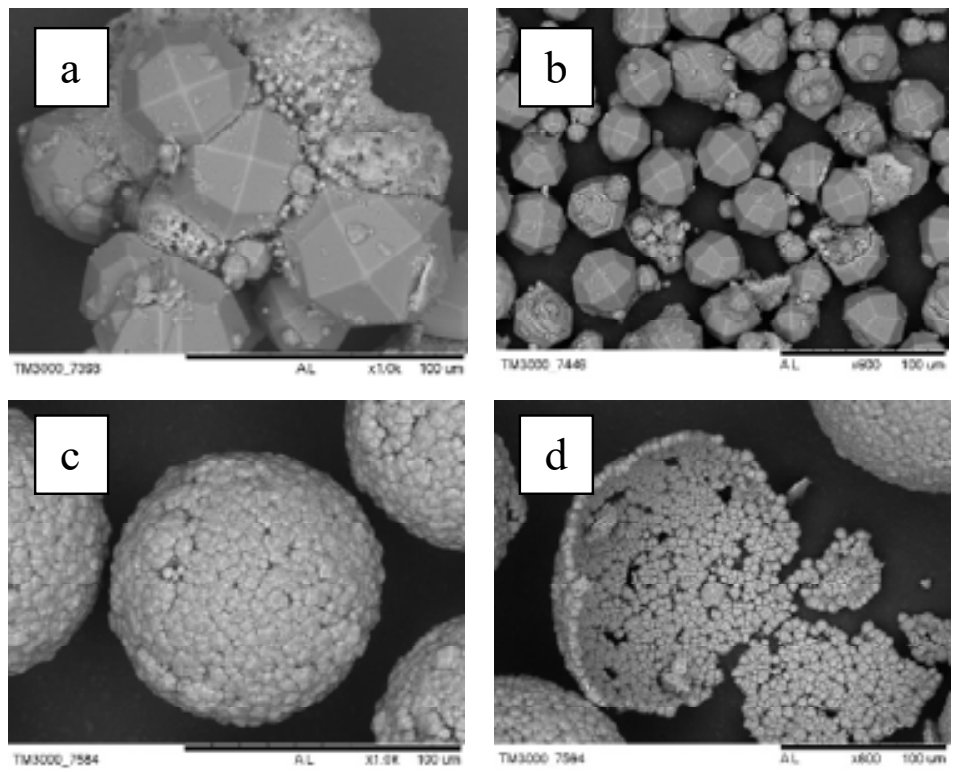

Рис. 2. РЭМ-снимки продуктов синтеза в автоклаве $\mathbf{A 1}(\mathrm{a}, \mathrm{b})$ и автоклаве $\mathbf{A 2}$ (c, d) для системы $\mathrm{Na}_{2} \mathrm{O}-\mathrm{H}_{2} \mathrm{O}$ $\left(\mathrm{SiO}_{2}-\mathrm{Al}_{2} \mathrm{O}_{3}\right)_{\text {стекло }}$

Fig. 2. SEM images of products of syntheses in autoclave $\mathbf{A 1}(\mathrm{a}, \mathrm{b})$ and autoclave $\mathbf{A 2}$ (c, d) for the $\mathrm{Na}_{2} \mathrm{O}-\mathrm{H}_{2} \mathrm{O}-$ $\left(\mathrm{SiO}_{2}-\mathrm{Al}_{2} \mathrm{O}_{3}\right)_{\text {glass }}$ system

микросфер и размер кристаллов анальцима и позволило получить однородный по составу и строению микросферический материал.

Детальный рентгеноструктурный анализ (РСА) полученных фаз анальцима был проведен авторами в работах $[18,19]$, которые свидетельствуют о том, что единственной цеолитной фазой, обнаруженной в обоих продуктах синтеза, является кубический анальцим (пр. гр. Ia-3d) состава $\mathrm{Na}_{0.986}\left(\mathrm{Al}_{0.986} \mathrm{Si}_{2.014} \mathrm{O}_{6}\right)\left(\mathrm{H}_{2} \mathrm{O}\right)_{0.977}(\mathbf{A 1})$ и $\mathrm{Na}_{0.989} \mathrm{Al}_{0.989} \mathrm{Si}_{2.011} \mathrm{O}_{6} \mathrm{H}_{2} \mathrm{O}_{0.981}$ (A2).

На рис. 3 представлены РЭМ-снимки узких фракций продуктов синтеза в системе $\mathrm{Na}_{2} \mathrm{O}$ $\mathrm{ZrO}_{2}-\mathrm{H}_{2} \mathrm{O}-\left(\mathrm{SiO}_{2}-\mathrm{Al}_{2} \mathrm{O}_{3}\right)_{\text {стекло }}$ Детальные исследования морфологии и состава всех фракций, выделенных из автоклава А1, проведены в работе [18]. Было показано, что только продукт белого цвета (А1-Б) содержит частицы с икоситетраэдрическим габитусом, типичным для кристаллов анальцима. Рассев продукта А1-Б позволил сконцентрировать во фракции 36-71 однородную по размеру часть продукта, содержащую анальцим с максимумом распределения частиц по размеру около $40 \mu \mathrm{M}$ (рис. $3 a, 6$ ) [18].

В работе [18] методом РСА, рентгенофотоэлектронной спектроскопии, РЭМ и РСМА показано, что во фракции 36-71 $\mu$ анальцим является единственной цеолитной фазой состава $\mathrm{Na}_{0.95}\left(\mathrm{Al}_{0.95} \mathrm{Si}_{2.05} \mathrm{O}_{6}\right)\left(\mathrm{H}_{2} \mathrm{O}\right)_{0.946}$, а его кристаллы содержат примерно 5 мас. \% аморфного диоксида циркония, распределенного в объеме цеолитной матрицы (рис. 4). Методом РСА также установлено, что фазы анальцима, кристаллизующиеся в системах $\mathrm{Na}_{2} \mathrm{O}-\mathrm{H}_{2} \mathrm{O}-\left(\mathrm{SiO}_{2}-\mathrm{Al}_{2} \mathrm{O}_{3}\right)_{\text {стекло и }}$ $\mathrm{Na}_{2} \mathrm{O}-\mathrm{ZrO}_{2}-\mathrm{H}_{2} \mathrm{O}-\left(\mathrm{SiO}_{2}-\mathrm{Al}_{2} \mathrm{O}_{3}\right)_{\text {стекло }}$, идентичны по своей кристаллической структуре с небольшим отличием в отношении $\mathrm{Si} / \mathrm{Al}$.

В другом режиме синтеза, реализованном в автоклаве А2 как при низкой (30 и 50 об/мин), так и высокой (200 об/мин) скоростях перемешивания реакционной смеси, также формируются 
частицы кубического анальцима, но значительно меньшего размера и с дефектной структурой кристалла (рис. $3 c-f$ ). По данным PCMA, содержание Zr в частицах анальцима составляет около 4.5 мас. \%. Присутствие фазы кубического анальцима во всех продуктах синтеза в качестве основной цеолитной фазы подтверждается данными РФА, которые представлены на рис. 5 на примере образца, полученного при 200 об/мин.

Оценка размеров частиц Zr-содержащего анальцима на основании РЭМ-снимков показала, что размер большинства частиц, полученных при разных скоростях перемешивания, примерно одинаков и составляет около $6 \mu$ м.

Проведена оценка возможности использования продуктов синтеза в качестве сорбентов PЗЭ на примере $\mathrm{Nd}^{3+}$ как имитатора актиноидов (III). Определены изотермы сорбции катионов неодима для индивидуального и композитного анальцима, полученных в автоклаве $\mathbf{A 2}$ при 50 об/мин (ANA-50 и Zr-ANA-50 соответственно) (рис. 6).

Рассчитанные с помощью модели Ленгмюра такие характеристики, как предельная сорбция $\left(\mathrm{a}_{\mathrm{m}}\right)$, коэффициент распределения $\left(\mathrm{K}_{\mathrm{D}}\right)$ и эффективность сорбции $(\mathrm{E})$, приведены в табл. 2. Полученные значения указывают на удовлетворительные равновесные параметры процесса сорбции $\mathrm{Nd}^{3+}$ из разбавленных растворов.

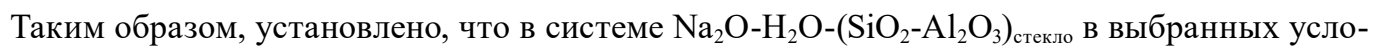
виях гидротермальной обработки $\left(150{ }^{\circ} \mathrm{C}, 48\right.$ ч) в качестве основной формируется фаза кубиче-
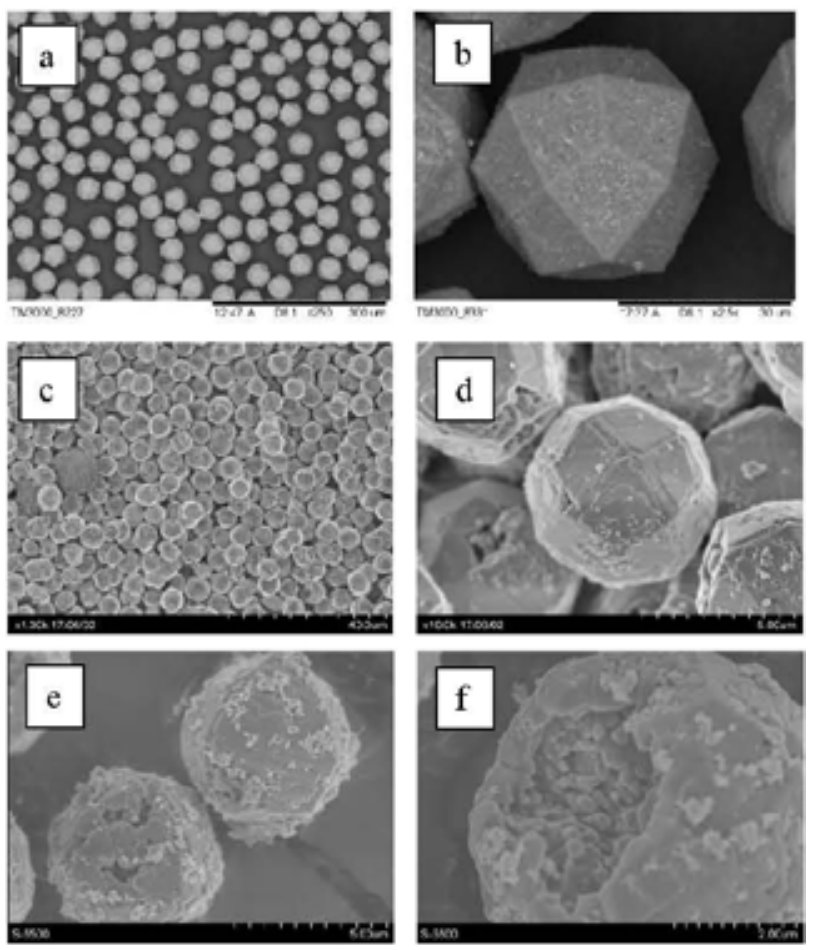

Рис. 3. РЭМ-снимки продуктов синтеза в автоклаве $\mathbf{A 1}(\mathrm{a}, \mathrm{b})$ и в автоклаве $\mathbf{A 2}$, полученных при 50 об/мин $(\mathrm{c}, \mathrm{d})$ и 200 об/мин (e, f), для системы $\mathrm{Na}_{2} \mathrm{O}-\mathrm{ZrO}_{2}-\mathrm{H}_{2} \mathrm{O}-\left(\mathrm{SiO}_{2}-\mathrm{Al}_{2} \mathrm{O}_{3}\right)_{\text {стекло }}$

Fig. 3. SEM images of products of syntheses in autoclave $\mathbf{A 1}(\mathrm{a}, \mathrm{b})$ and autoclave $\mathbf{A 2}$ at $50 \mathrm{~min}^{-1}(\mathrm{c}, \mathrm{d})$ and $200 \mathrm{~min}^{-1}(\mathrm{e}, \mathrm{f})$ for the $\mathrm{Na}_{2} \mathrm{O}-\mathrm{ZrO}_{2}-\mathrm{H}_{2} \mathrm{O}-\left(\mathrm{SiO}_{2}-\mathrm{Al}_{2} \mathrm{O}_{3}\right)_{\text {glass }}$ system 

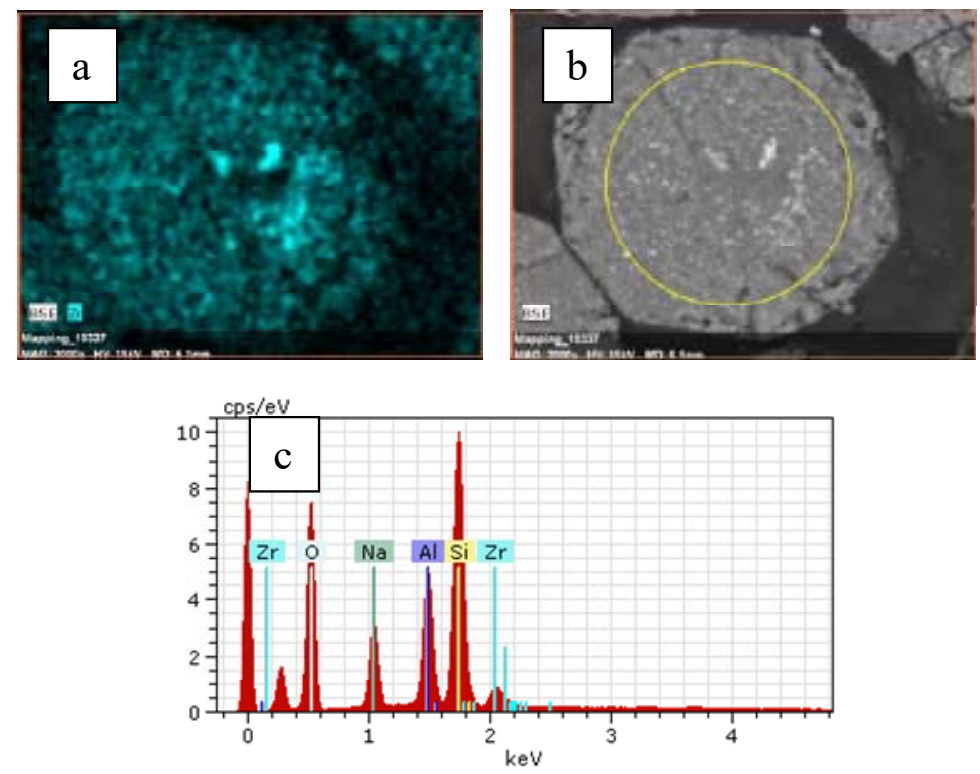

Рис. 4. Карта распределения циркония (a) и EDX-спектр для полированного среза (b, c) кристалла анальцима, полученного в системе $\mathrm{Na}_{2} \mathrm{O}-\mathrm{ZrO}_{2}-\mathrm{H}_{2} \mathrm{O}-\left(\mathrm{SiO}_{2}-\mathrm{Al}_{2} \mathrm{O}_{3}\right)_{\text {стекло }}$

Fig. 4. Map of zirconium distribution (a) and EDX-spectrum of a polished cross-section (b, c) of an analcime crystal crystallized in the $\mathrm{Na}_{2} \mathrm{O}-\mathrm{ZrO}_{2}-\mathrm{H}_{2} \mathrm{O}-\left(\mathrm{SiO}_{2}-\mathrm{Al}_{2} \mathrm{O}_{3}\right)_{\text {glass }}$ system

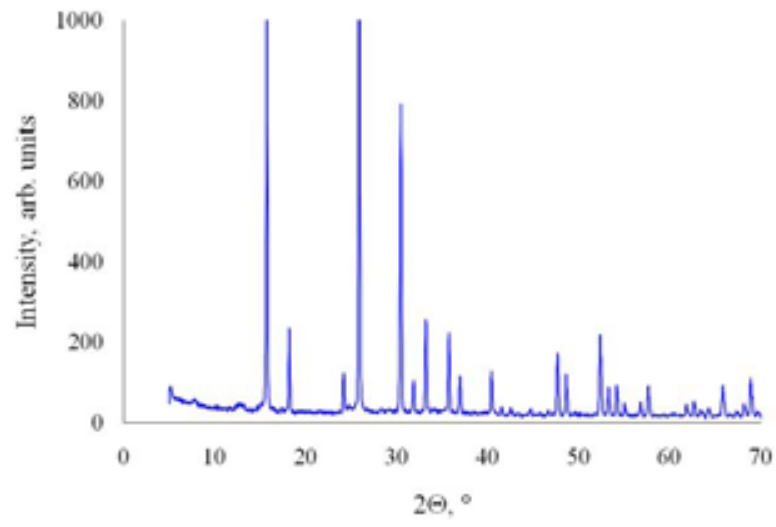

Рис. 5. Дифрактограмма продукта $<36 \mu$, полученного в автоклаве $\mathbf{A 2}$ при скорости перемешивания 200 об/мин

Fig. 5. X-ray diffraction pattern for the product $<36 \mu \mathrm{m}$ synthesized in $\mathbf{A 2}$ autoclave at a rotation rate of $200 \mathrm{~min}^{-1}$

ского анальцима, размеры которой определяются режимом перемешивания реакционной смеси. Проведение синтеза при перемешивании в горизонтальной плоскости позволяет получать однородный микросферический материал в виде полых микросфер с толщиной стенки до $7 \mu$ м, состоящей из кристаллов анальцима размером 2-7 точной стеклофазы. При введении в эту систему циркония протекает кристаллизация индивидуальных частиц кубического анальцима, содержащего включения аморфного $\mathrm{ZrO}_{2}$, с узким распределением частиц по размеру с максимумами 40 $\mu$ м (Режим А1) и 6

$$
-356-
$$



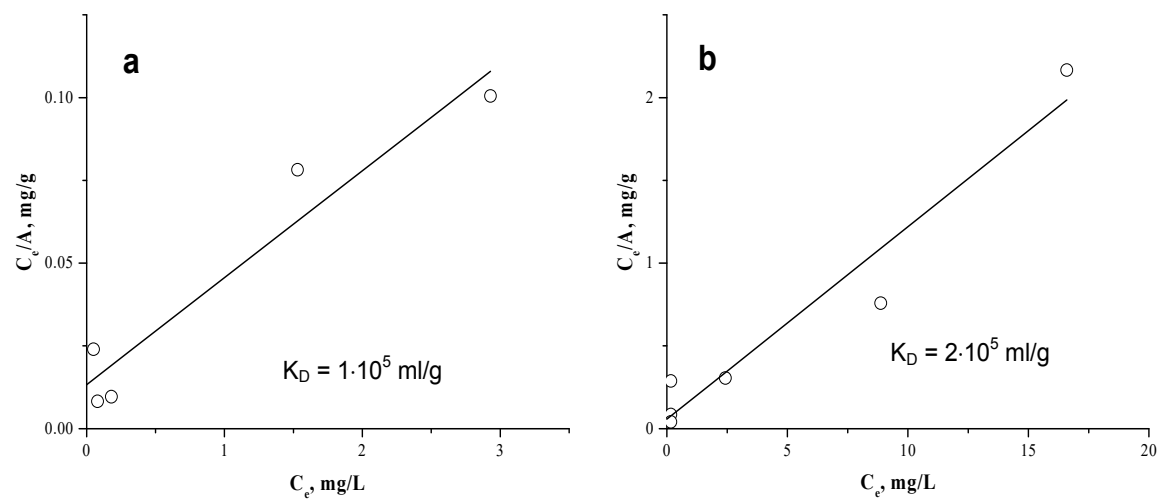

Рис. 6. Изотермы сорбции $\mathrm{Nd}^{3+}$ для анальцима (а) и $\mathrm{Zr}$-содержащего анальцима (b) при $20{ }^{\circ} \mathrm{C}$ (точки эксперимент, линии - модель Ленгмюра)

Fig. 6. Isotherms of $\mathrm{Nd}^{3+}$ sorption for analcime (a) and $\mathrm{Zr}$-bearing analcime (b) at $20{ }^{\circ} \mathrm{C}$ (points - experiment, lines - Langmuir fit)

Таблица 2. Параметры уравнения Ленгмюра для процесса сорбции $\mathrm{Nd}^{3+}$ на анальциме и $\mathrm{Zr-coдержащем}$ анальциме

Table 2. Parameters of Langmuir equation for $\mathrm{Nd}^{3+}$ sorption on analcime and $\mathrm{Zr}$-bearing analcime

\begin{tabular}{|c|c|c|c|}
\hline Образец & $\mathrm{a}_{\mathrm{m}}, \mathrm{M \Gamma} / \Gamma$ & $\mathrm{K}_{\mathrm{D}}, \mathrm{M} / / \Gamma$ & $\mathrm{E}, \%$ \\
\hline ANA-50 & 15.9 & $1 \cdot 10^{5}$ & 99.3 \\
Zr-ANA-50 & 33.8 & $2 \cdot 10^{5}$ & 99.6 \\
\hline
\end{tabular}

при практически количественном превращении стекла микросфер. Анальцим и композитный $\mathrm{Zr-coдержащий} \mathrm{анальцим} \mathrm{эффективно} \mathrm{сорбируют} \mathrm{катионы} \mathrm{Nd}^{3+}$ из разбавленных растворов с $\mathrm{K}_{\mathrm{D}} \sim 10^{5} \mathrm{мл} / \mathrm{\Gamma}$.

\section{Микросферическая композиция $\mathrm{ZrMo}_{2} \mathrm{O}_{7}(\mathrm{OH})_{2}\left(\mathrm{H}_{2} \mathrm{O}\right)_{2} @\left(\mathrm{SiO}_{2}-\mathrm{Al}_{2} \mathrm{O}_{3}\right)_{\text {стекло }}$}

На рис. 7 приведены РЭМ-снимки исходного микросферического носителя (рис. 7a), микросферической композиции (рис. $7 b$ ) и покрытия, сформированного на поверхности носителя (рис. $7 c, d$ ).

Представленные данные в совокупности с результатами РФА и рентгеноспектрального микроанализа (рис. 7e, $f$ ) [39] свидетельствуют о формировании на поверхности носителя наноструктурированной фазы тетрагонального молибдата циркония $\mathrm{ZrMo}_{2} \mathrm{O}_{7}(\mathrm{OH})_{2}\left(\mathrm{H}_{2} \mathrm{O}\right)_{2}$ (a = 11.446 (1) $\AA ; \mathrm{c}=12.490$ (2) $\AA$ ) [28], состоящего из удлиненных кристаллитов толщиной 20-100 нм и длиной 100-800 нм. Удельная площадь поверхности микросферической композиции составила $15.3 \mathrm{~m}^{2} /$, что более чем на порядок выше аналогичной величины для микросферического носителя $\left(\mathrm{S}^{\text {Бэт }}=0.7\right.$ м $\left.^{2} / \Gamma\right)$. Учитывая, что фаза $\mathrm{ZrMo}_{2} \mathrm{O}_{7}(\mathrm{OH})_{2}\left(\mathrm{H}_{2} \mathrm{O}\right)_{2}$ не обладает микропористой и/или канальной структурой [28], повышенная удельная площадь поверхности композиции, скорее всего, обусловлена наличием в поверхностном слое наноразмерных межкристаллитных пор. 

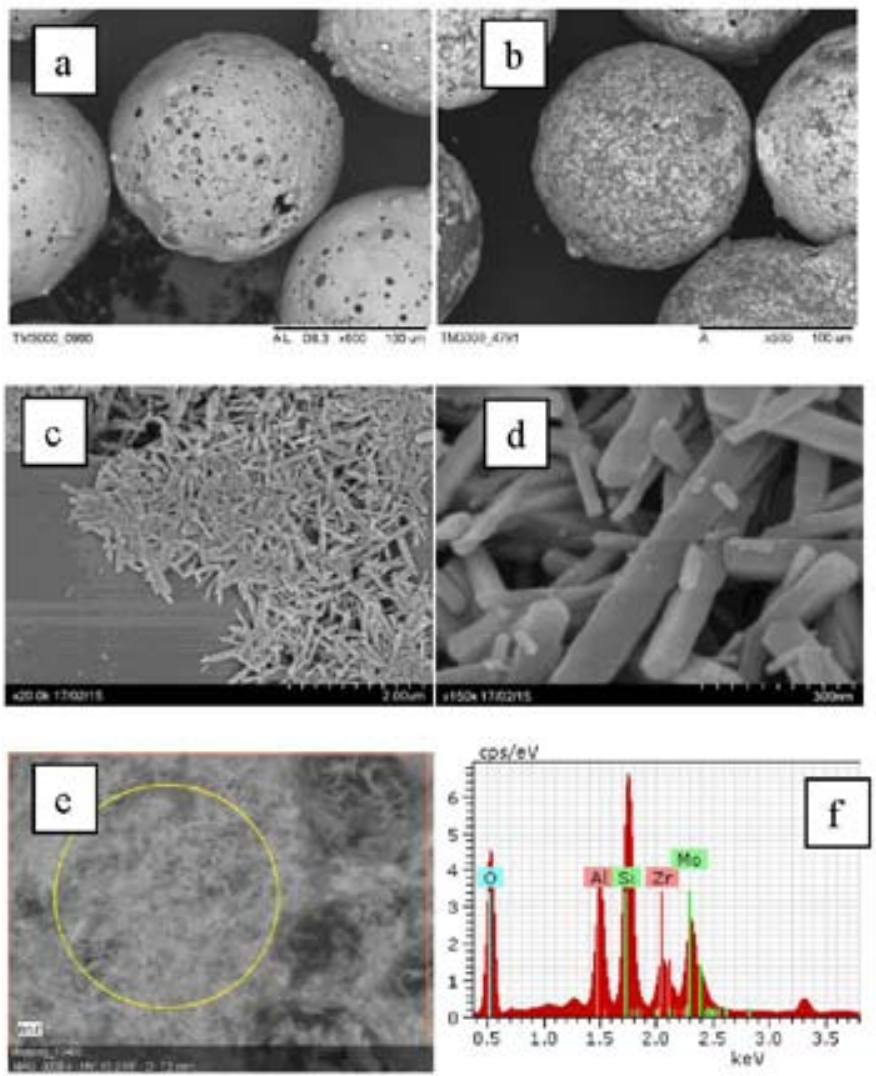

Рис. 7. РЭМ-снимки микросферического носителя (а), микросферической композиции $\mathrm{ZrMo}_{2} \mathrm{O}_{7}(\mathrm{OH})_{2}\left(\mathrm{H}_{2} \mathrm{O}\right)_{2} @$ $\left(\mathrm{SiO}_{2}-\mathrm{Al}_{2} \mathrm{O}_{3}\right)_{\text {стекло }}(\mathrm{b}), \mathrm{ZrMo}_{2} \mathrm{O}_{7}(\mathrm{OH})_{2}\left(\mathrm{H}_{2} \mathrm{O}\right)_{2}$ на поверхности носителя (c, d); EDX-спектр участка поверхности композиции (e, f)

Fig. 7. SEM images of a microsphere glass support (a), microsphere composite $\mathrm{ZrMo}_{2} \mathrm{O}_{7}(\mathrm{OH})_{2}\left(\mathrm{H}_{2} \mathrm{O}\right)_{2} @\left(\mathrm{SiO}_{2}{ }^{-}\right.$ $\left.\mathrm{Al}_{2} \mathrm{O}_{3}\right)_{\text {glass }}(\mathrm{b}), \mathrm{ZrMo}_{2} \mathrm{O}_{7}(\mathrm{OH})_{2}\left(\mathrm{H}_{2} \mathrm{O}\right)_{2}$ covering $(\mathrm{c}, \mathrm{d})$; EDX spectrum for designated region of the composite surface $(\mathrm{e}, \mathrm{f})$

Изучение сорбционных свойств микросферической композиции, содержащей фазу $\mathrm{ZrMo}_{2} \mathrm{O}_{7}(\mathrm{OH})_{2}\left(\mathrm{H}_{2} \mathrm{O}\right)_{2}$, в отношении катионов $\mathrm{Nd}^{3+}, \mathrm{Sr}^{2+}$ и $\mathrm{Cs}^{+}$показало, что материал сорбирует эти катионы с повышенным сродством к $\mathrm{Nd}^{3+}$ и незначительной емкостью в отношении $\mathrm{Cs}^{+}$ (рис. 8). Экспериментально полученные значения величины сорбции удовлетворительно описываются моделью Ленгмюра с $\mathrm{K}_{\mathrm{D}}$, снижающимся в ряду $\mathrm{Nd}^{3+}>\mathrm{Sr}^{2+}>\mathrm{Cs}^{+}$(рис. 8).

Авторами в работе [39] было сделано предположение, что сорбция катионов на $\mathrm{ZrMo}_{2} \mathrm{O}_{7}(\mathrm{OH})_{2}\left(\mathrm{H}_{2} \mathrm{O}\right)_{2}$ протекает за счет замещения атомов водорода в -OH-группах с одновременным вытеснением из структуры слабо связанных молекул воды согласно уравнению (5):

$$
\mathrm{ZrMo}_{2} \mathrm{O}_{7}(\mathrm{OH})_{2}\left(\mathrm{H}_{2} \mathrm{O}\right)_{2}+\mathrm{xNd}^{3+}=\mathrm{Nd}_{\mathrm{x}} \mathrm{ZrMo}_{2} \mathrm{O}_{7+3 \mathrm{x}}(\mathrm{OH})_{2-3 \mathrm{x}}\left(\mathrm{H}_{2} \mathrm{O}\right)_{2-\mathrm{x}}+3 \mathrm{xH}^{+}+\mathrm{xH}_{2} \mathrm{O}
$$

При этом возможность размещения катионов в позициях решетки, занятых молекулами воды, определяется размерными эффектами, в частности, межатомными расстояниями между молекулами воды и ближайшими атомами кислорода, равными 2.679-2.808 А̊. Расчетные дли- 

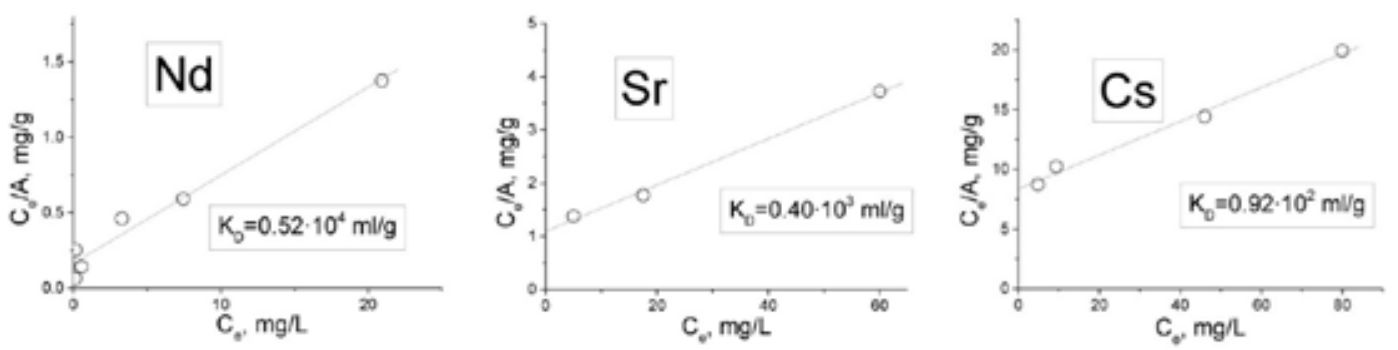

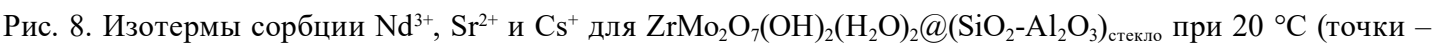
эксперимент, линии - модель Лэнгмюра)

Fig. 8. Isotherms of $\mathrm{Nd}^{3+}, \mathrm{Sr}^{2+}$ and $\mathrm{Cs}^{+}$sorption for $\mathrm{ZrMo}_{2} \mathrm{O}_{7}(\mathrm{OH})_{2}\left(\mathrm{H}_{2} \mathrm{O}\right)_{2} @\left(\mathrm{SiO}_{2}-\mathrm{Al}_{2} \mathrm{O}_{3}\right)_{\text {glass }}$ at $20{ }^{\circ} \mathrm{C}$ (points experiment, lines - Langmuir fit)

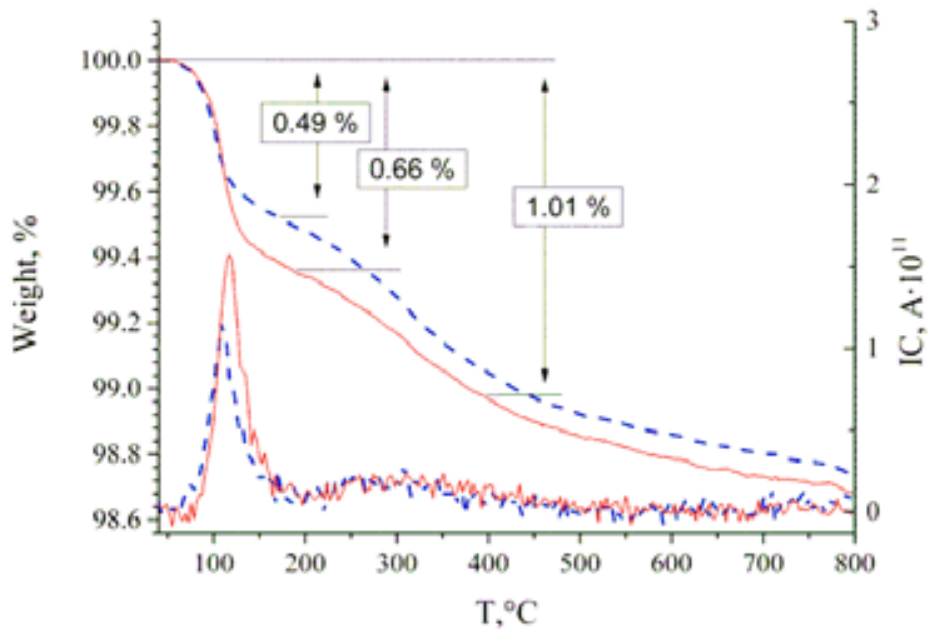

Рис. 9. Температурные зависимости величины ТГ сигнала и масс-спектральной интенсивности иона $\mathrm{H}_{2} \mathrm{O}^{+}$ для исходной композиции $\mathrm{ZrMo}_{2} \mathrm{O}_{7}(\mathrm{OH})_{2}\left(\mathrm{H}_{2} \mathrm{O}\right)_{2} @\left(\mathrm{SiO}_{2}-\mathrm{Al}_{2} \mathrm{O}_{3}\right)_{\text {стекло }}$ (сплошная линия) и $\mathrm{ZrMo}_{2} \mathrm{O}_{7}(\mathrm{OH})_{2}\left(\mathrm{H}_{2} \mathrm{O}\right)_{2} @$ $\left(\mathrm{SiO}_{2}-\mathrm{Al}_{2} \mathrm{O}_{3}\right)_{\text {стекло }}$ после сорбции $\mathrm{Nd}^{3+}$ (пунктирная линия, 18 мг $\mathrm{Nd} / \mathrm{r}$ )

Fig. 9. Temperature dependences of TG signals and mass-spectral intensity of $\mathrm{H}_{2} \mathrm{O}^{+}$-ions for initial $\mathrm{ZrMo}_{2} \mathrm{O}_{7}(\mathrm{OH})_{2}\left(\mathrm{H}_{2} \mathrm{O}\right)_{2} @\left(\mathrm{SiO}_{2}-\mathrm{Al}_{2} \mathrm{O}_{3}\right)_{\text {glass }}\left(\right.$ solid) and $\mathrm{Nd}^{3+}$-loaded $\mathrm{ZrMo}_{2} \mathrm{O}_{7}(\mathrm{OH})_{2}\left(\mathrm{H}_{2} \mathrm{O}\right)_{2} @\left(\mathrm{SiO}_{2}-\mathrm{Al}_{2} \mathrm{O}_{3}\right)_{\text {glass }}$ (dashed, $18 \mathrm{mg} \mathrm{Nd} / \mathrm{g}$ )

ны связей $\mathrm{Nd}-\mathrm{O}, \mathrm{Sr}-\mathrm{O}, \mathrm{Cs}-\mathrm{O}$ составляют $2.2506,2.5801,2.8626 \AA$ соответственно. Следовательно, этому критерию удовлетворяют только катионы $\mathrm{Nd}^{3+}$ и $\mathrm{Sr}^{2+}$, в то время как катион цезия ввиду большего размера не способен встраиваться в кристаллическую решетку.

Дополнительное свидетельство сорбции $\mathrm{Nd}^{3+}$ в соответствии с предполагаемым механизмом получено из данных термического анализа индивидуальной фазы $\mathrm{ZrMo}_{2} \mathrm{O}_{7}(\mathrm{OH})_{2}\left(\mathrm{H}_{2} \mathrm{O}\right)_{2}$ до и после сорбции $\mathrm{Nd}^{3+}$ [39]. На рис. 9 представлены температурные зависимости величины ТГ сигнала и масс-спектральной интенсивности иона $\mathrm{H}_{2} \mathrm{O}^{+}$для композиции $\mathrm{ZrMo}_{2} \mathrm{O}_{7}(\mathrm{OH})_{2}\left(\mathrm{H}_{2} \mathrm{O}\right)_{2} @$ $\left(\mathrm{SiO}_{2}-\mathrm{Al}_{2} \mathrm{O}_{3}\right)_{\text {стекло. }}$.

Видно, что на ТГ-кривых наблюдается два пика выделения воды - пик $75-200{ }^{\circ} \mathrm{C}$, соответствующий протеканию реакции разложения молибдата циркония (уравнение (6)), и пик при 200-400 들 обусловленный дегидроксилированием стекла подложки. 


$$
\mathrm{ZrMo}_{2} \mathrm{O}_{7}(\mathrm{OH})_{2}\left(\mathrm{H}_{2} \mathrm{O}\right)_{2}=\mathrm{ZrMo}_{2} \mathrm{O}_{8}+3 \mathrm{H}_{2} \mathrm{O} \text {. }
$$

Как и ожидалось, сорбция $\mathrm{Nd}^{3+}$ привела к снижению убыли количества воды при $75-200{ }^{\circ} \mathrm{C}$ (уравнение (6)) с $\Delta \mathrm{m}=0.66$ до $\Delta \mathrm{m}=0.49 \%$, что указывает на различное содержание воды в композиции до и после сорбции $\mathrm{Nd}^{3+}$.

Таким образом, методом двухстадийного гидротермального синтеза получено наноструктурированное циркономолибдатное покрытие состава $\mathrm{ZrMo}_{2} \mathrm{O}_{7}(\mathrm{OH})_{2}\left(\mathrm{H}_{2} \mathrm{O}\right)_{2}$ на поверхности микросферического носителя на основе полых алюмосиликатных микросфер (структура «ядро/ оболочка»). Установлено, что микросферическая композиция проявляет повышенную сорбционную способность в отношении катионов $\mathrm{Cs}^{+}, \mathrm{Sr}^{2+}$ и $\mathrm{Nd}^{3+}$ по сравнению с индивидуальной микроразмерной фазой $\mathrm{ZrMo}_{2} \mathrm{O}_{7}(\mathrm{OH})_{2}\left(\mathrm{H}_{2} \mathrm{O}\right)_{2}$, а также селективность в отношении $\mathrm{Nd}^{3+}$ или $\mathrm{Sr}^{2+}$ в присутствии $\mathrm{Cs}^{+}$с $\mathrm{K}_{\mathrm{D}}$ порядка $10^{4}$ и $10^{3}$ мл/г соответственно.

\section{Выводы}

Получены новые Zr-содержащие материалы для процессов сорбционного извлечения катионов металлов из жидких токсичных отходов, включая радиоактивные, с использованием узких фракций алюмосиликатных микросфер летучих зол с высоким содержанием стеклофазы (91-95 мас. \%), способных выполнять функцию источника $\mathrm{Si}$ и $\mathrm{Al}$ в синтезе микропористых алюмосиликатов и прекурсора микросферической подложки в синтезе материалов типа «ядрооболочка».

Определены условия синтеза композитного материала на основе кубического анальцима, содержащего включения аморфного $\mathrm{ZrO}_{2}$, с узким распределением частиц по размеру с максимумами $\sim 40$ и $\sim 6 \mu$ м, который эффективно сорбирует катионы $\mathrm{Nd}^{3+}$ из разбавленных растворов с $\mathrm{K}_{\mathrm{D}} \sim 10^{5} \mathrm{M} / / \Gamma$.

Получены наноструктурированные циркономолибдатные покрытия состава $\mathrm{ZrMo}_{2} \mathrm{O}_{7}(\mathrm{OH})_{2}\left(\mathrm{H}_{2} \mathrm{O}\right)_{2}$ на микросферических подложках на основе микросфер системы $\mathrm{SiO}_{2}-\mathrm{Al}_{2} \mathrm{O}_{3}$ разного состава (структура «ядро/оболочка»). Микросферические композиции проявляют повышенное сродство к катионам $\mathrm{Nd}^{3+}$ и $\mathrm{Sr}^{2+}$, что позволяет проводить их сорбционное извлечение из водных сред с $\mathrm{K}_{\mathrm{D}}$ порядка $10^{4} \mathrm{Mл} /$ г.

Работа выполнена за счет средств Федерального бюджета на реализацию проекта № V.45.3.3 в рамках программы ФНИ ГАН на 2013-2020 г2. Авторы выражают благодарность сотрудникам ИХХТ СО РАН О.А. Левицкой и В.Р. Кузик за выполнение анализа ИСП-МС и ААС, Л.А. Соловьеву за проведение РФА и РСА, А.М. Жижаеву за проведение анализа РЭМЭДС полированных срезов, В.В. Юмашеву за измерение удельной площади поверхности.

\section{Список литературы}

1. Брек Д. Цеолитовые молекулярные сита: Пер. с англ. М.: Мир, 1976. 606 с. [Brek D. Zeolitic molecular sieves: Trans. from English. Moscow: Mir, 1976. 606 p. (In Russ.)]

2. Амфлет Ч. Неорганические иониты: Пер. с англ. М.: Мир, 1966. 188 с. [Amphlet, C. Inorganic Ionites: Trans. from English. Moscow: Mir, 1966. 188 p. (In Russ.)]

3. Pabalan R.T., Bertetti F.P. Cation-exchange properties of natural zeolites. Reviews in Mineralogy and Geochemistry 2001. Vol. 45, P. 453-518. 
4. Moirou A., Vaxevanidou A., Christidis G.E., Paspaliaris I. Ion exchange of zeolite Na-P $\mathrm{P}_{\mathrm{c}}$ with $\mathrm{Pb}^{2+}, \mathrm{Zn}^{2+}$, and $\mathrm{Ni}^{2+}$ ions. Clays and Clay Minerals 2000. Vol. 48, P. 563-571.

5. El-Kamash A.M. Evaluation of zeolite A for the sorptive removal of $\mathrm{Cs}^{+}$and $\mathrm{Sr}^{2+}$ ions from aqueous solutions using batch and fixed bed column operations. Journal of Hazardous Materials 2008. Vol. 151, P. 432-445.

6. Borai E.H., Harjula R., Malinen L., Paajanen A. Efficient removal of cesium from low-level radioactive liquid waste using natural and impregnated zeolite minerals. Journal of Hazardous Materials 2009. Vol. 172, P. 416-422.

7. Sachse A., Merceille A., Barré Y., Grandjean A.,Fajula F., Galarneau A. Macroporous LTAmonoliths for in-flow removal of radioactive strontium from aqueous effluents: Application to the case of Fukushima. Microporous Mesoporous Materials 2012. Vol. 164, P. 251-258.

8. Cappelletti P., Rapisardo G., Gennaro B., ColellaA., Langellac A., Graziano F.S., Bish D.L., Gennaro M. Immobilization of $\mathrm{Cs}$ and $\mathrm{Sr}$ in aluminosilicate matrices derived from natural zeolites. Journal of Nuclear Materials 2011. Vol. 414, P. 451-457.

9. Barrer R.M. Ion-exchange and ion-sieve processes in crystalline zeolites. Journal of Chemical Society 1950. Vol. 0, P. 2342-2350.

10. Rachkova N.G., Shuktomova I.I. Sorption of U(VI) and Ra from aqueous solutions with analcime-containing rock. Radiochemistry 2011. Vol. 52, Р. 76-80.

11. Шушков Д.А., Шуктомова И.И. Сорбция радиоактивных элементов цеолитсодержащими породами. Известия Коми научного иентра УрО РАН 2013. Вып. 1(13), С. 69-73 [Shushkov D.A., Shuktomova I.I. Sorption of radioactive elements by zeolite-containing rocks. Proceedings of the Komi Science Centre UB RAS 2013. Vol. 1 (13), P. 69-73 (In Russ.)]

12. Баррер Р. Гидротермальная химия цеолитов: Пер. с англ. М.: Мир, 1985. 424 с. [Barrer R. Hydrothermal Chemistry of Zeolites: Trans. from English. Moscow, Mir, 1985. 424 p. (In Russ.)]

13. Fan J., Jing Z., Zhang Y., Miao J., Chen Y., Jin F. Mild hydrothermal synthesis of pollucite from soil for immobilization of $\mathrm{Cs}$ in situ and its characterization. Chemical Engineering Journal 2016. Vol. 304, P. 344-350.

14. Hegazy E.Z., Abd El Maksod I.H., Abo El Enin R.M.M. Preparation and characterization of Ti and V modified analcime from local kaolin. Applied Clay Science 2010. Vol. 49, P. 149-155.

15. Fang J.-N., Lin I.-C., Lo H.-J., Song S.-R., Chen Y.-L.The kinetics of analcime synthesis in alkaline solution. Journal of the Chinese Chemical Society 2004. Vol. 51, P. 1267-1272.

16. Dyer A., Tangkawanit S., Rangsriwatananon K. Exchange diffusion of $\mathrm{Cu}^{2+}, \mathrm{Ni}^{2+}, \mathrm{Pb}^{2+}$ and $\mathrm{Zn}^{2+}$ into analcime synthesized from perlite. Microporous and Mesoporous Materials 2004. Vol. 75, P. 273-279.

17. Querol X., Moreno N., Urnana J.C., Alastuey A., Hernandez E., Lopez Soler A., Plana F. Synthesis of zeolites from coal fly ash: an overview. International Journal of Coal Geology 2002. Vol. 50, P. 413-423.

18. Vereshchagina T.A., Kutikhina E.A., Solovyov L.A., Vereshchagin S.N., Mazurova E.V., Chernykh Y.Yu., Anshits A.G. Synthesis and structure of analcime and analcime-zirconia composite derived from coal fly ash cenospheres. Microporous and Mesoporous Materials 2018. Vol. 258, P. $228-235$. 
19. Vereshchagina T.A., Kutikhina E.A., Chernykh Y.Yu., Solovyov L.A., Zhizhaev A.M., Vereshchagin S.N., Anshits A.G. One-step immobilization of cesium and strontium from alkaline solutions via a facile hydrothermal route. Journal of Nuclear Materials 2018. Vol. 510, P. $243-255$.

20. Begley E.R., Herndon P.O. Zirconia-alumina-silica refractories. Refractory Materials 1971. Vol. 5, P. 185-208.

21. Donald I.W. Waste immobilization in glass and ceramic based hosts: radioactive, toxic and hazardous wastes. - Wiley-Blackwell Chichester: John Wiley \& Sons, 2010. 507 p.

22. Vereshchagina T.A., Vereshchagin S.N., Shishkina N.N., Solovyov L.A., Vasilieva N.G., Anshits A.G. Microsphere zeolite materials derived from coal fly ash cenospheres as precursors to mineral-like aluminosilicate hosts for ${ }^{135,137} \mathrm{Cs}$ and ${ }^{90} \mathrm{Sr}$. Journal of Nuclear Materials 2013. Vol. 437, P. 11-18.

23. Dragan E.S.Advanced separations by specialized sorbents. CRC Press, Taylor\&Francis Group, 2015. $358 \mathrm{p}$.

24. Xu X., Xiao L., Haugen N. O., Wu Z., Jia Y., Zhong W., Zou J. High humidity response property of sol-gel synthesized $\mathrm{ZnFe}_{2} \mathrm{O}_{4}$ films. Materials Letters 2018. Vol. 213, P. 266-268.

25. Vereshchagina T.A., Vereshchagin S.N., Shishkina N.N., Solovyov L.A., Mikhaylova O.A., Anshits A.G. Microporous and Mesoporous Materials 2013. Vol. 169, P. 207-211.

26. Kutikhina E. A., Mazurova E.V., Parfenov V.A., Fomenko E.V., Vereshchagina T.A. Microsphere zirconomolybdate sorbents for extraction of lanthanides (III) from aqueous solutions. Journal of Siberian Federal University. Chemistry 2017(10). Vol. 3, P. 311-324.

27. Vereshchagina T.A., Fomenko E.V., Vasilieva N.G., Solovyov L.A., Vereshchagin S.N., Bazarova Z.G., Anshits A.G. A novel layered zirconium molybdate as a precursor to a ceramic zirconomolybdate host for lanthanide bearing radioactive waste. Journal of Material Chemistry 2011. Vol. 21, P. 12001-12007.

28. Clearfield A., Blessing R.H. The preparation and crystal structure of a basic zirconium molybdate and its relationship to ion exchange gels. Journal of Inorganic and Nuclear Chemistry 1972. Vol. 34, P. 2643-2663.

29. Anshits N.N., Vereshchagina T.A., Bayukov O.A., Salanov A.N., Anshits A.G. The nature of nanoparticles of crystalline phases in cenospheres and morphology of their shells. Glass Physics and Chemistry 2005. Vol. 31, P. 306-315.

30. Trens P., Hudson M.J., Denoyel R. Formation of mesoporous zirconium (IV) oxides of controlled surface areas. Journal of Material Chemistry 1998. Vol. 8, P. 2147-2152.

31. Greg S.J., Singh K.S.W. Adsorption, surface area, porosity. 2nd ed., Academic Press, London, 1982. $304 \mathrm{p}$.

32. Cements and materials for cement production. Chemical analysis methods, State Standard (GOST) No.5382-91. IPK Izdatel'stvo standartov, Moscow, 2002.

33.Reitveld H. A profile refinement method for nuclear and magnetic structures. Journal of Applied Crystallography 1969. Vol. 2, P. 65-71.

34.Solovyov L.A. Full-profile refinement by derivative difference minimization. Journal of Applied Crystallography 2004. Vol. 37, P. 743-749.

35. Onishi H., Nagai H., Toyta Y. Spectrophotometric determination of rare earth elements and thorium with arsenazo. Analytica Chimica Acta 1962. Vol. 26, P. 528-531. 
36. Fomenko E.V., Anshits N.N., Vasil'eva N.G., Rogovenko E.S., Mikhaylova O.A., Mazurova E.V., Solovyev L.A., Anshits A.G. Solid Fuel Chemistry 2016. Vol. 50, P.238-247.

37. Barrer R.M. Hydrothermal chemistry of zeolites. New York: Academic Press, 1982. 360 p.

38. Wise W.S. Handbook of natural zeolites, Under Ed. C. Colella, International Zeolite Association, Natural Zeolites Commission, Napoli, Italy, A. De FredeEdotore: Natural Zeolites Commission, 2013. $126 \mathrm{p}$.

39. Vereshchagina T.A., Kutikhina E.A., Fomenko E.V., Solovyov L.A., Vereshchagin S.N., Anshits A.G. $\mathrm{ZrMo}_{2} \mathrm{O}_{7}(\mathrm{OH})_{2}\left(\mathrm{H}_{2} \mathrm{O}\right)_{2}$ coated microsphere glass supports derived from coal fly ash cenospheres as a novel sorbent for radionuclide trapping. Journal of Environmental Chemical Engineering 2019. Vol. 7, P. 102887. 